\title{
Vitamin $D$ status and peripheral arterial disease: evidence so far
}

\author{
This article was published in the following Dove Press journal: \\ Vascular Health and Risk Management \\ I4 November 201 I \\ Number of times this article has been viewed
}

\section{GT Chua \\ YC Chan \\ SW Cheng}

Division of Vascular Surgery, Department of Surgery,

University of Hong Kong Medical

Centre, Queen Mary Hospital,

Pokfulam, Hong Kong
Correspondence: Yiu Che Chan

Division of Vascular and Endovascular

Surgery, Department of Surgery,

University of Hong Kong Medical Centre,

South Wing, 14th Floor Block K,

Queen Mary Hospital, Pokfulam,

Hong Kong

Tel +852 22554962

Fax +852 22554961

Email ycchan88@ hkucc.hku.hk
Background: Vitamin D deficiency has recently been implicated as a contributory factor in the development of peripheral arterial disease (PAD).

Methods: A review of the published literature on PAD and vitamin D was undertaken using Medline, PubMed, and Embase, and cross-referenced. All relevant published papers on the subject were reviewed.

Results: Published studies have shown that there is a significant association between vitamin D and PAD. Populations with lower vitamin D levels are more likely to develop PAD in a graded manner. Higher amputation rates are also observed among patients with PAD and lower vitamin D levels. In addition, vitamin D deficiency is significantly associated with increased risk of cardiovascular adverse events. This was also observed in the mouse model where low vitamin D led to the development of atherosclerosis.

Conclusion: This study shows that vitamin D deficiency could be an independent risk factor for the development of PAD and that this risk factor is easily correctable. Further studies should look into the effects of vitamin D supplementation in patients with PAD.

Keywords: peripheral arterial disease, claudication, gangrene, vitamin D deficiency, amputation, cardiovascular risk factors

\section{Introduction}

It is now more than 75 years since the discovery of calciferol, known commonly as vitamin D, and of its ability to cure rickets in animals and children. ${ }^{1-3}$ Recent epidemiologic and clinical studies have indicated that vitamin D may have far more roles than just in the prevention of rickets. Diseases such as osteoporosis, muscle weakness, several types of cancer, diabetes, hypertension, and cardiovascular disease may all result from subtle and chronic vitamin D deficiency. ${ }^{4}$

Vitamin D is a generic name for a group of fat-soluble steroids of which the two major forms are vitamin $\mathrm{D}_{2}$ (ergocalciferol) and vitamin $\mathrm{D}_{3}$ (cholecalciferol). ${ }^{5}$ Vitamin $\mathrm{D}$, or calciferol, without a subscript, refers to either $\mathrm{D}_{2}, \mathrm{D}_{3}$, or both. In 1919, a British doctor, Edward Mellanby, noticed that dogs fed cod liver oil did not develop rickets and concluded that cod liver oil could prevent the disease. ${ }^{6}$ In 1921, Elmer McCollum tested modified cod liver oil in which the vitamin A had been destroyed, which also cured sick dogs, so McCollum concluded that the factor in cod liver oil which cured rickets was distinct from vitamin A. ${ }^{7-9}$ It was called "vitamin D" because it was the fourth vitamin to be named, following an alphabetical code. The molecular geometry of vitamin $D_{2}$ was determined in $1932^{10}$ and that of vitamin $D_{3}$ in 1936 as a result of ultraviolet irradiation of 7-dehydrocholesterol. ${ }^{11}$ 


\section{Measurements of serum vitamin D levels}

The concentration of 25-hydroxyvitamin D (25-OHD) is commonly used for measurement of serum vitamin $\mathrm{D}$ levels, despite the active form being 1,25-OHD. This is because parathyroid hormone will increase renal conversion when there is an insufficiency, causing the active form to be normal or elevated. Therefore, vitamin D status is better reflected by 25-OHD. However, measurement of 25-OHD levels may not be accurate in patients with severe renal diseases (creatinine clearance less than $15 \mathrm{~mL} / \mathrm{min}$ or undergoing dialysis), as renal conversion of 25-OHD level is reduced. Hence, parathyroid hormone levels should also be taken into account when identifying vitamin $\mathrm{D}$ deficiency. ${ }^{12}$

There is no consensus regarding the cut-off level for vitamin D deficiency. It has been suggested previously that vitamin $\mathrm{D}$ deficiency in adults should be defined as a serum 25-OHD level below $50 \mathrm{nmol} / \mathrm{L}(20 \mathrm{ng} / \mathrm{mL}) .{ }^{12,13}$ However, further research suggests that optimal serum 25-OHD status should be maintained above $80 \mathrm{nmol} / \mathrm{L}$ (32 ng/mL), because the risk for various medical conditions, including reduced bone density, periodontal disease, colon cancer, hypertension, and impaired lung function, is lowest above this level. The risk of undiagnosed diabetes and impaired glucose tolerance was also found to be lowest when the serum 25-OHD level was above $83 \mathrm{nmol} / \mathrm{L}$; while that of myocardial infarction was lowest when serum 25-OHD was above $107 \mathrm{nmol} / \mathrm{L}{ }^{13}$

Technically, there are still some uncertainties about the optimal method for measuring vitamin D levels. Multiple methodologies for 25-OHD measurement (radioimmunoassay, high-performance liquid chromatography, and liquid chromatography tandem mass spectroscopy) are available and subject to variability, which causes difficulties in defining the cut-off value for vitamin D insufficiency or deficiency. Therefore, aiming at a higher 25-OHD level seems to be clinically safe and reasonable, as it improves vitamin D status with minimal risks. ${ }^{14}$ Most laboratories have increased the lower limit of the reference range to $75 \mathrm{nmol} / \mathrm{L}(30 \mathrm{ng} / \mathrm{mL})$. In addition, 25-OHD level varies with seasons, exposure to sunlight, and dietary intake. ${ }^{15}$ Therefore, unless issues such as choice of assay, timing of measurement, and reference range are clearly addressed, the optimal method of measuring vitamin D level remains uncertain.

\section{Literature search method and results}

A literature review using standard databases including PubMed, Medline, and Embase was performed in March
2011, searching for studies on peripheral arterial disease and vitamin D and its analogs performed since 2000. The search was conducted using the keywords "peripheral arterial disease" (PAD) and "vitamin D." Inclusion criteria were: systematic reviews and meta-analysis, journal reviews, cohort, case-control studies and population studies, and English-language articles where the full text was available. Commentaries and letters to the editor were excluded.

Twenty-three articles were initially identified and 13 of these excluded. Five articles had no full text available, five articles were irrelevant to the topic, two articles were letters to the editor, and one was commentary. The remaining ten articles were included for review. These included journal reviews, longitudinal, and cross-sectional studies, written in English with full text available. Publications on the relationships between vitamin $\mathrm{D}$ and cardiovascular risk factors, cardiovascular diseases, and peripheral arterial disease were carefully reviewed. Other relevant articles were also crossreferenced.

\section{Vitamin D deficiency and cardiovascular risk factors}

Vitamin D deficiency has been shown in various studies to be associated with an increase in the prevalence of various cardiovascular risk factors. ${ }^{16-19}$ Vitamin D deficiency is inversely correlated with body mass index, hypertension, diabetes mellitus, and hyperlipidemia (total cholesterol and triglyceride). ${ }^{16}$ When subjects were categorized into normal $(>30 \mathrm{ng} / \mathrm{mL}$ or $75 \mathrm{nmol} / \mathrm{L})$, low (16-30 $\mathrm{ng} / \mathrm{mL}$ or $40-75 \mathrm{nmol} / \mathrm{L}$ ) or very low ( $\leq 15 \mathrm{ng} / \mathrm{mL}$ or $37.5 \mathrm{nmol} / \mathrm{L}$ ) vitamin D level groups, it was also found that there were highly significant graded inverse associations with hypertension, hyperlipidemia, diabetes mellitus, and PAD. In addition, there was an increase in hazard ratios for these cardiovascular risk factors between individuals with very low and normal vitamin D levels, which remained statistically significant after adjustment. ${ }^{17}$

In a randomized placebo-controlled double-blind trial, Witham et al found that one single dose of high-dose vitamin $\mathrm{D}_{2}$ improves endothelial function, as assessed by flow-mediated dilatation of the brachial artery in response to 5 minutes of forearm occlusion. ${ }^{18}$ Values were significantly higher in the intervention group at 8 weeks' follow-up, despite the blood pressures of subjects not being significantly affected during the short-term follow-up period of 16 weeks. ${ }^{18,19}$

Vitamin D inadequacy has also been shown to be inversely correlated with the proliferation of vascular smooth muscle cells, ${ }^{20,21}$ inflammatory effects upon arterial endothelial cells, and with increased carotid intima-media thickness. ${ }^{22,23}$ 
Vitamin D deficiency is linked to adverse morphological changes in large arteries, even in children. ${ }^{24}$ Low vitamin $\mathrm{D}$ has been shown to affect survival rate independently of vascular calcification and stiffness. ${ }^{25}$ Calcification can be induced by 1,25-OHD in cultured arterial smooth muscle cells. ${ }^{26}$ Arterial calcification is common in patients with diabetes and end-stage renal failure with peripheral arterial disease, and paricalcitol, a vitamin D receptor agonist, has been shown to improve survival for renal failure patients in comparison to traditional calcitriol therapy. ${ }^{27}$ Reik et al found that 1,25-OHD affects macrophages by lowering acetylated and oxidized low-density lipoprotein uptake in type 2 diabetic patients, thus reducing foam-cell formation and subsequently atherosclerosis. ${ }^{28}$ In addition, 1,25-OHD can induce cell-cycle arrest and apoptosis, an important process in the development of atherosclerosis and in some normal and malignant cell types. ${ }^{29}$ More recently, vitamin D deficiency has been associated with peripheral vascular disease, ${ }^{30}$ and may be an important contributory factor in the development of peripheral arterial disease in different ethnicities.

Gaddipati et al reviewed the possible mechanisms and role of vitamin D in vascular health. ${ }^{30}$ Vitamin D decreases blood pressure through the renin-angiotensin system. ${ }^{31}$ Vitamin D deficiency is inversely related to vascular smooth muscle proliferation and increase in carotid intima-media thickness. However, excessive vitamin D may do more harm than good, as excessive dietary consumption is potentially angiotoxic. ${ }^{32}$ Such toxicity can lead to vascular calcification and arterial stiffness. Norman and Powell showed that 1,25-OHD (which is the active form of vitamin D) interacts with vitamin $D$ receptors and directly or indirectly regulates the expression of a number of proteins relevant to the arterial wall, such as vascular endothelial growth factor, matrix metalloproteinase type 9, myosin, and elastin, and type I collagen. Cultured arterial smooth muscles can also undergo calcification when treated with $1,25-\mathrm{OHD}$, through a mechanism relying on suppression of parathyroid hormone-related peptide, which is an endogenous inhibitor of calcification, and parathyroid hormone-receptor signaling. Directly or indirectly, vitamin D exposure may downregulate the paracrine mechanism that normally protects the vasculature from calcification. ${ }^{33}$

\section{Vitamin D deficiency and cardiovascular diseases}

Cardiovascular diseases and adverse events are significantly higher in subjects with very low vitamin D levels. These conditions include coronary artery disease, heart failure, atrial fibrillation, PAD, stroke, myocardial infarction; the rate of death is also significantly higher in subjects with very low vitamin D levels. ${ }^{17,34,35}$ In another study, Wang et al also analyzed the relationship between vitamin D and risk of cardiovascular disease, and found that participants with 25-OHD levels $<15 \mathrm{ng} / \mathrm{mL}$ (37.5 nmol/L) had a higher incidence of cardiovascular events compared with those with $25-\mathrm{OHD}>15 \mathrm{ng} / \mathrm{mL}$, with a hazard ratio (HR) of 1.62. Similar observations were made in participants with hypertension $(\mathrm{HR}=2.13,95 \%$ confidence interval $[\mathrm{CI}] 1.30-3.48)$, but there were no significant differences between participants without hypertension $(\mathrm{HR}=1.04,95 \%$ CI $0.55-1.96)$. A graded inverse relationship between cardiovascular risk and 25-OHD level was also observed in this study. ${ }^{36}$ These results suggest that vitamin D deficiency may potentially become a future risk factor for cardiovascular diseases.

However, these results may not be conclusive. A recent systematic review and meta-analysis was unable to demonstrate a statistically significant reduction in mortality and cardiovascular risks, including stroke and myocardial infarction, but the quality of the available evidence was low to moderate at best. ${ }^{37}$ However, another systematic review by Grandi et al showed significant results. ${ }^{38}$ Therefore, clinical association between vitamin $\mathrm{D}$ and cardiovascular risks and events should be further investigated and supported by high-quality evidence.

\section{Vitamin D deficiency and peripheral arterial disease}

Recent studies have suggested that vitamin D may have a direct relationship with PAD. ${ }^{16,39-40}$ Reis et al performed a cross-sectional study based on the National Health and Nutrition Examination Survey 2001-2004, investigating racial differences in vitamin $\mathrm{D}$ levels and the incidence of PAD between black and white populations. ${ }^{39}$ The authors concluded that Afro-Caribbean populations were at higher risk of vitamin D deficiency, possibly due to greater cutaneous melanin content, lower dietary intake, and racial differences in vitamin $\mathrm{D}$ metabolism. They also showed that vitamin D concentrations were significantly lower in blacks that in whites $(P<0.001)$ and PAD was significantly more prevalent among black adults than white $(8.5 \%$ and $5.3 \%$ respectively, $P<0.05$ ), with the odds ratio being 2.11. After adjustment for demographic factors and cardiovascular risk factors (diabetes, hypertension, hypercholesterolemia, C-reactive protein, estimated glomerulofiltration rate, and history of cardiovascular disease), the odds ratio remained significant at 1.67. In contrast, adjustment for serum 25-OHD concentration yielded insignificant results. 
Serum vitamin D level has been shown to have an inverse relationship with the prevalence of PAD in a graded manner. Melamed et al studied the association between 25-OHD levels and prevalence of PAD, and found that for each $10 \mathrm{ng} / \mathrm{mL}$ decrease in 25-OHD, the prevalence ratio of PAD was $1.35(95 \%$ CI 1.15-1.59) after multivariable adjustment. Furthermore, vitamin $\mathrm{D}$ deficiency increases the amputation rate in patients with PAD. ${ }^{40}$ Gaddipati et al showed that individuals with vitamin D deficiency $(<20 \mathrm{ng} / \mathrm{mL}$ ) had a significantly higher amputation rate compared with those who were not defined as vitamin D deficient $(6.7 \%$ and $4.2 \%, P=0.029) .{ }^{16}$

\section{Experimental evidence}

Emerging laboratory evidence supports the idea of a direct relationship between vitamin D and PAD. Oral supplementation of vitamin $\mathrm{D}_{3}$ has been shown to suppress atherosclerosis in a mouse model. Takeda et al tested apolipoprotein E-knock-out mice with calcitriol and demonstrated that higher doses of calcitriol reduced the formation of atherosclerotic lesions by $39.1 \%$, which was significantly more than those in the control group. It was shown in the atherosclerotic lesions that more regulatory T-cells (Tregs) and less mature dendritic cells are present compared with the control group. ${ }^{41}$ Studies have shown that Tregs suppress the inflammatory responses of effector T-cells, which are suggested to be potentially proatherogenic, while dendritic cells stimulate the differentiation of naive T-cells to effector T-cells. ${ }^{21,42,43}$ In addition, Takeda et al has also demonstrated that suppression of Tregs has resulted in an increase in atherosclerotic lesions. This showed that oral vitamin $\mathrm{D}_{3}$ reduces atherosclerosis by the suppression of inflammatory cells in mice, which warrants confirmation of such benefits in humans. ${ }^{41}$

All the above findings imply that vitamin D deficiency is an important direct contributor to PAD in a dose-related manner and proper supplementation could possibly reverse the disease. Vitamin D deficiency could also affect subsequent adverse events.

\section{Limitations of the current review}

There are several limitations to this review. Firstly, most of the studies included were population-based, cross-sectional, or longitudinal studies. Only associations, not causal relationships, could be established between vitamin D and PAD. Although most studies concluded that vitamin D deficiency was a potential risk factor of PAD, it was also sensible to think that vitamin D deficiency could be a complication of PAD as a result of impaired mobility and subsequent lack of sunlight exposure. Secondly, there was a lack of information about certain aspects in these studies, including the geographical location of residence, seasonal variations during which blood samples were obtained, and measurement of parathyroid hormone, which were significant confounding variables. Thirdly, these studies were targeted to Western populations. The associations between vitamin D and PAD in Asians or other ethnic populations, such as those of Arabic descent, remain unclear. Currently, there is still no levelone evidence or any randomized-controlled trials studying whether vitamin D supplementation is useful in reducing the rate or the risk of developing PAD, so a systematic review or meta-analysis of randomized-controlled trials is not yet possible.

\section{Conclusion}

Emerging studies are showing that there is an association between low vitamin D levels and PAD, with animal models suggesting possible mechanisms. Future studies should focus on various ethnic populations, and investigate whether vitamin $\mathrm{D}$ should be recommended for prevention of PAD, and if so, at what dosage. Only randomized controlled trials will be able to provide the answers.

\section{Disclosure}

The authors report no conflicts of interest in this work.

\section{References}

1. Bruce HM, Callow RK. Interaction of vitamin D and dietary factors in the healing of rickets in rats. Biochem J. 1934;28(2):512-516.

2. Heymann W. Nitrogen, potassium, sodium, and chloride metabolism in rickets, with special reference to biliary fistula in puppies. J Exp Med. 1936;64(3):471-483.

3. Krestin D. Prophylaxis of rickets by single massive doses of vitamin D. Br Med J. 1945;1(4385):78-80.

4. Zerwekh JE. Blood biomarkers of vitamin D status. Am J Clin Nutr. 2008;87(4):1087S-1091S.

5. Arnold A. The biological activity of calciferol (vitamin D2). Proc Soc Exp Biol Med. 1946;63(2):230-233.

6. Mellanby E. The relation of diet to health and disease. Br Med J. 1930; 1(3614):677-681.

7. McClean FC, Budy AM. Vitamin A, Vitamin D, cartilage, bones, and teeth. In: Harris RS. Vitamins and Hormones. Vol 21. London: Academic Press; 1963:51-52.

8. Holt LE. A tribute to Elmer V. McCollum. Am J Clin Nutr. 1968;21(10): $1136-1137$.

9. Nutrition classics. The Journal of Nutrition, Volume 91, 1967: The paths to the discovery of vitamins A and D. By Elmer Verner McCollum. Nutr Rev. 1986;44(7):242-244.

10. Windaus A, Linsert O, Luttringhaus A, Weidlinch G. Uber das krystallistierte Vitamin $\mathrm{D}_{2}$. [About the crystallized Vitamin D2.] Justis Liebigs Ann Chem. 1932;492:226-231. [German.]

11. Brockmann, H. Die Isolierung des antirachitischen Vitamins aus Thunfischleberol. [The isolation of the antirachitic vitamin from tuna liver.] Physiol Chem. 1936:241:104-115. [German.]

12. Fosnight SM, Zafirau WJ, Hazelett SE. Vitamin D supplementation to prevent falls in the elderly: evidence and practical considerations. Pharmacotherapy. 2008;28(2):225-234 
13. Scragg R, Bartley J. Vitamin D-how do we define deficiency and what can we do about it in New Zealand? N Z Med J. 2007;120(1262):U2735.

14. Holick MF, Binkley NC, Bischoff-Ferrari HA, et al. Evaluation, treatment, and prevention of vitamin D deficiency: an Endocrine Society Clinical Practice Guideline. J Clin Endocrinol Metab. 2011;96(7): 1911-1930.

15. Rosen CJ. Clinical practice. Vitamin D insufficiency. $N$ Engl J Med. 2011;364(3):248-254.

16. Gaddipati VC, Bailey BA, Kuriacose R, Copeland RJ, Manning T, Peiris AN. The relationship of vitamin D status to cardiovascular risk factors and amputation risk in veterans with peripheral arterial disease. J Am Med Dir Assoc. 2011;12(1):58-61.

17. Anderson JL, May HT, Horne BD, et al. Relation of vitamin D deficiency to cardiovascular risk factors, disease status, and incident events in a general healthcare population. Am J Cardiol. 2010;106(7):963-968.

18. Witham MD, Dove FJ, Sugden JA, Doney AS, Struthers AD. The effect of vitamin D replacement on markers of vascular health in stroke patients - A randomised controlled trial. Nutr Metab Cardiovasc Dis. 2010 Dec 29. Epub ahead of print.

19. Corretti MC, Anderson TJ, Benjamin EJ, et al. Guidelines for the ultrasound assessment of endothelial-dependent flow-mediated vasodilation of the brachial artery: a report of the International Brachial Artery Reactivity Task Force. J Am Coll Cardiol. 2002;39(2):257-265.

20. Mitsuhashi T, Morris RC Jr, Ives H. 1,25-dihydroxyvitamin D3 modulates growth of vascular smooth muscle cells. J Clin Invest. 1991;87(6): 1889-1895.

21. Mascitelli L, Goldstein MR, Grant WB. Does vitamin D have a role in reducing the risk of peripheral artery disease? Mayo Clin Proc. 2010; 85(11):1058-1059.

22. SuzukiY, Ichiyama T, Ohsaki A, Hasegawa S, Shiraishi M, Furukawa S. Anti-inflammatory effect of 1alpha, 25-dihydroxyvitamin $\mathrm{D}(3)$ in human coronary arterial endothelial cells: Implication for the treatment of Kawasaki disease. J Steroid Biochem Mol Biol. 2009;113(1-2): 134-138.

23. Targher G, Bertolini L, R Padovani, et al. Serum 25-hydroxyvitamin D3 concentrations and carotid artery intima-media thickness among type 2 diabetic patients, Clin Endocrinol (Oxf). 2006;65(5):593-597.

24. Shroff R, Egerton M, Bridel M, et al. A bimodal association of vitamin $\mathrm{D}$ levels and vascular disease in children on dialysis. J Am Soc Nephrol. 2008;19(6):1239-1246.

25. Barreto DV, Barreto FC, Liabeuf S, et al. Vitamin D affects survival independently of vascular calcification in chronic kidney disease. Clin J Am Soc Nephrol. 2009;4(6):1128-1135.

26. Jono S, Nishizawa Y, Shioi A, Morii H. 1,25-Dihydroxyvitamin D3 increases in vitro vascular calcification by modulating secretion of endogenous parathyroid hormone-related peptide. Circulation. 1998; 98(13):1302-1306.

27. Teng M, Wolf M, Lowrie E, Ofsthun N, Lazarus J, Thadhani R. Survival of patients undergoing hemodialysis with paricalcitol or calcitriol therapy. N Eng J Med. 2003;349(5):446-456.
28. Riek AE, Oh J, Bernal-Mizrachi C. Vitamin D regulates macrophage cholesterol metabolism in diabetes. J Steroid Biochem Mol Biol. 2010; 121(1-2):430-433.

29. Sinha S, Eddington H, Kalra PA. Vascular calcification: lessons from scientific models. J Ren Care. 2009;35 Suppl 1:51-56.

30. Gaddipati VC, Kuriacose R, Copeland R, Bailey BA, Peiris AN Vitamin D deficiency: an increasing concern in peripheral arterial disease. J Am Med Dir Assoc. 2010;11(5):308-311.

31. Li YC, Kong J, Wei M, Chen ZF, Liu SQ, Cao LP. 1,25-Dihydroxyvi$\operatorname{tamin} \mathrm{D}(3)$ is a negative endocrine regulator of the renin-angiotensin system. J Clin Invest. 2002;110(2):229-238.

32. Toda T, Ito M, Toda Y, Smith T, Kummerow F. Angiotoxicity in swine of a moderate excess of dietary vitamin D3. Food Chem Toxicol. 1985; 23(6):585-592.

33. Norman PE, Powell JT. Vitamin D, shedding light on the development of disease in peripheral arteries. Arterioscler Thromb Vasc Biol. 2005;25(1):39-46.

34. Poole KE, Loveridge N, Barker PJ, et al. Reduced vitamin D in acute stroke. Stroke. 2006;37(1):243-245.

35. Barakat K, Hitman GA. The emerging role of vitamin D and its receptor in the pathogenesis of acute coronary syndromes. $\mathrm{Br} J$ Cardiol. 2006;13:9-12.

36. Wang TJ, Pencina MJ, Booth SL, et al. Vitamin D deficiency and risk of cardiovascular disease. Circulation. 2008;117(4):503-511.

37. Elamin MB, Elnour NO, Elamin KB, et al. Vitamin D and cardiovascular outcomes: a systematic review and meta-analysis. $J$ Clin Endocrinol Metab. 2011;96(7):1931-1942.

38. Grandi NC, Breitling LP, Brenner H. Vitamin D and cardiovascular disease: systematic review and meta-analysis of prospective studies. Prev Med. 2010;51(3-4):228-233.

39. Reis JP, Michos ED, von Mühlen D, Miller ER 3rd. Differences in vitamin $\mathrm{D}$ status as a possible contributor to the racial disparity in peripheral arterial disease. Am J Clin Nutr. 2008;88(6):1469-1477.

40. Melamed ML, Muntner P, Michos ED, et al. Serum 25-hydroxyvitamin D levels and the prevalence of peripheral arterial disease: results from NHANES 2001 to 2004. Arterioscler Thromb Vasc Biol. 2008;28(6): 1179-1185.

41. Takeda M, Yamashita T, Sasaki N, et al. Oral administration of an active form of vitamin D3 (calcitriol) decreases atherosclerosis in mice by inducing regulatory $\mathrm{T}$ cells and immature dendritic cells with tolerogenic functions. Arterioscler Thromb Vasc Biol. 2010;30(12):2495-2503.

42. Ait-Oufella H, Salomon BL, Potteaux S, et al. Natural regulatory T cells control the development of atherosclerosis in mice. Nat Med. 2006; 12(2):178-180.

43. Mallat $Z$, Gojova A, Brun V, et al. Induction of a regulatory $T$ cell type 1 response reduces the development of atherosclerosis in apolipoprotein E-knockout mice. Circulation. 2003;108(10):1232-1237.
Vascular Health and Risk Management

\section{Publish your work in this journal}

Vascular Health and Risk Management is an international, peerreviewed journal of therapeutics and risk management, focusing on concise rapid reporting of clinical studies on the processes involved in the maintenance of vascular health; the monitoring, prevention and treatment of vascular disease and its sequelae; and the involvement of

\section{Dovepress}

metabolic disorders, particularly diabetes. This journal is indexed on PubMed Central and MedLine. The manuscript management system is completely online and includes a very quick and fair peer-review system, which is all easy to use. Visit http://www.dovepress.com/ testimonials.php to read real quotes from published authors. 